\title{
Is thrombolytic therapy in acute inferior myocardial infarction really better than conventional treatment?
}

\author{
Tom J M Tobé
}

One of the unresolved issues surrounding thrombolysis is whether this intervention is less effective in inferior myocardial infarction. ${ }^{1}$ Because of the large number of patients studied in various clinical trials I believe that we are now in a position to analyse outcome according to the site of infarction.

\section{Statistical considerations in short-term survival studies ( $<5$ weeks)}

ISIS-2 showed that mortality after streptokinase treatment alone was $7 \cdot 2 \%$, compared with $8 \cdot 8 \%$ (NS) after conventional treatment without aspirin. ${ }^{2}$ A heterogeneity test performed in this retrospective subgroup analysis for electrocardiographic site of infarction was not significant. Therefore, a lack of statistical power might have accounted for this apparent lack of benefit (type II error), and a true treatment effect might have been hidden. ${ }^{3}$

The Italian GISSI trial gave comparable results in inferior myocardial infarction. ${ }^{4}$ Mortality after treatment with streptokinase was $6.8 \%$ and after conventional treatment it was $7 \cdot 2 \%$ (NS, no data on heterogeneity were provided). In the USIM trial, the use of urokinase in inferior myocardial infarction was associated with a significantly higher mortality than conventional treatment (mortality after urokinase was $5.8 \% \quad v \quad 3.2 \%$ after conventional treatment, $P=0.04$, no data on heterogeneity were provided). ${ }^{5}$

The data of these three trials were incorporated into a recent meta-analysis of trials in which more than 1000 patients were randomised to thrombolytic therapy and conventional treatment (GISSI-1, ISAM, AIMS (APSAC intervention mortality study), ISIS2, ASSET (Anglo-Scandinavian study of early thrombolysis), USIM, ISIS-3, EMERAS, LATE). ${ }^{6}$ Mortality in inferior myocardial infarction was $7 \cdot 5 \%$ after thrombolytic therapy compared with $8.4 \%$ in controls (NS) $\left(\chi^{2}\right.$ test of odds ratios for heterogeneity $=21.286$ degrees of freedom, $P<0.01)$. This probability suggests that the likelihood of finding differences between subgroups by chance alone is less than $1 \%$. It could be regarded as evidence that in all 9 trials the effect in inferior myocardial infarc- tion was in the same direction, leading to the conclusion that thrombolytic therapy has no effect on mortality in inferior myocardial infarction, which was defined as ST elevation in the inferior leads. (Simultaneous ST elevation in the inferior and anterior leads was analysed separately and in this group thrombolytic therapy had a significant effect, which is not discussed here.) Furthermore, a recent study showed that alteplase (tissue plasminogen activator) was no more effective than streptokinase in terms of mortality in inferior myocardial infarction. ${ }^{7}$

\section{Pathophysiological considerations}

The drawback of retrospective subgroup analysis is the risk of false negative or false positive results. For example in ISIS-2 subdivision of the patients by astrological birth sign seemed to indicate that for patients born under Gemini or Libra aspirin had a slightly adverse effect on mortality, whereas in patients born under all other astrological birth signs it had a strikingly beneficial effect. ${ }^{2}$ None the less, when there are good reasons why a treatment effect could be absent in a particular subgroup, the absence of a beneficial effect in a subgroup analysis becomes more likely to be a true negative result.

Treatment with thrombolytic agents reduces total creatine kinase $M B$ release, as shown by a smaller area under the $\mathrm{CK} M B$ curve, and this reflects better preservation of left ventricular function. ${ }^{8}$ Though several studies unanimously show that thrombolysis has a significant effect on left ventricular function in anterior myocardial infarction, these studies do not unanimously show that thrombolysis has the same effect on left ventricular function in inferior myocardial infarction..$^{9-13}$

There are several explanations why thrombolysis may be of less benefit in inferior myocardial infarction.

- The left ventricular mass at risk is smaller in inferior than in anterior myocardial infarction, leaving less tissue to be salvaged. ${ }^{14}$

- Patency rates after thrombolytic therapy are lower in inferior than in anterior myocardial infarction. ${ }^{9}$

- Collateral circulation is more prominent in 
inferior myocardial infarction than in anterior myocardial infarction. ${ }^{915}$ In patients in whom thrombolytic therapy fails to induce reperfusion, the presence of collateral circulation is associated with limitation of infarct size. ${ }^{16}$ Therefore, achievement of reperfusion in inferior myocardial infarction may not be paralleled by the same effect in terms of myocardial salvage as it is in anterior myocardial infarction.

\section{Long-term survival}

The beneficial effect of thrombolytic therapy obtained within the first weeks after acute myocardial infarction was maintained during the subsequent 6-15 months. ${ }^{217-19}$ In another study, this benefit continued for five years. ${ }^{20}$ Though it is suggested that the difference between the two treatment groups increased somewhat over time, after five years the difference between conventional treatment and streptokinase was still not significant for those with inferior myocardial infarction. This subgroup analysis, however, was in a small study (total 533 patients, 278 of whom had inferior myocardial infarction). ${ }^{20}$

\section{Side effects}

Thrombolytic therapy was associated with an excess of four strokes per 1000 patients, and this rate was independent of the site of infarction. ${ }^{6}$ Of these strokes, two are already accounted for in the overall mortality reduction. Therefore, in inferior myocardial infarction treatment with thrombolytic therapy causes two additional strokes (non-fatal) per 1000 patients compared with conventional treatment. ${ }^{6}$

Thrombolytic therapy is associated with three additional bleeds requiring transfusion for every 1000 patients treated. ${ }^{2}$

\section{Conclusion}

Whereas thrombolytic therapy reduces mortality during the first five weeks after anterior myocardial infarction, there is no evidence that it reduces mortality in inferior myocardial infarction. On the basis of statistical and pathophysiological evidence, it seems likely that the absence of effect in inferior myocardial infarction is real-that is, a true negative result. Furthermore, thrombolysis causes a significant number of strokes and serious bleeds.

Because thrombolysis in inferior myocardial infarction (ST elevation confined to the inferior leads) is not more effective than conventional treatment and because it is associated with more and serious side effects, I believe that patients with inferior myocardial infarction should be given conventional treatment and not thrombolysis.

1 Braunwald E. Thrombolytic reperfusion of acute myocardial infarction: resolved and unresolved issues. $7 \mathrm{Am}$ Coll Cardiol 1988;12:85A-92A.

2 ISIS-2 (Second International Study of Infarct Survival) Collaborative Group). Randomised trial of intravenous streptokinase, oral aspirin, both, or neither among 17187 cases of suspected acute myocardial infarction: ISIS-2. Lancet 1988;ii:349-60.

3 Peto R, Pike MC, Armitage P, et al. Design and analysis of randomized clinical trials requiring prolonged observation of each patient. $B r \mathcal{F}$ Cancer 1977;35:1-39.

4 Gruppo Italiano per lo Studio della Streptochinasi nell'Infarto Miocardico (GISSI). Effectiveness of intravenous thrombolytic treatment in acute myocardial infarction. Lancet 1986; i:397-401.

5 Rossi P, Bolognese L, on behalf of Urochinasi per via Sistemica nell'Infarto Miocardico (USIM) Collaborative Group. Comparison of intravenous urokinase plus heparin versus heparin alone in acute myocardial infarc-
tion. Am $\mathcal{F}$ Cardiol 1991;69:585-592.

6 Fibrinolytic Therapy Trialists' (FFT) Collaborative Group. Indications for fibrinolytic therapy in suspected acute myocardial infarction: collaborative overview of early mortality and major morbidity results from all randomised trials of more than 1000 patients. Lancet 1994;343:311-22.

7 GUSTO Investigators. An international randomized trial comparing four thrombolytic strategies for acute myocardial infarction. N Engl f Med 1993;329:673-82.

8 ISAM Study Group. A prospective trial of intravenous streptokinase in acute myocardial infarction (ISAM). N Engl F Med 1986;314:1465-71.

9 Martin GV, Sheehan FH, Stadius M, et al. Intravenous streptokinase for acute myocardial infarction. Effects on global and regional systolic function. Circulation 1988;78:258-266.

10 Bassand JP, Machecourt J, Cassagnes J, et al. Multicenter trial of intravenous anisoylated plasminogen streptokinase activator complex (APSAC) in acute myocardial nase activator complex (APSAC) in acute myocardial infarction: effects on infarct size and left v

11 White HD, Norris RM, Brown MA, et al. Effect of intravenous streptokinase on left ventricular function and early survival after acute myocardial infarction. $N$ Engl $f$ Med 1987;317:850-5.

12 Bassand JP, Faivre R, Becque O, et al. Effects of early high-dose streptokinase intravenously on left ventricular function in acute myocardial infarction. Am $\mathcal{F}$ Cardiol 1987;60:435-439.

13 Guerci $\mathrm{AD}$, Gerstenblith, Brinker JA, et al. A randomized trial of tissue plasminogen activator for acute myocardial infarction with subsequent randomization to elective coronary angioplasty. $N$ Engl $\mathcal{F}$ Med 1987;317:

14 Kalbfleisch H, Hort W. Quantitative study on the size of coronary artery supplying areas postmortem. Am Heart 1977;94:183-8.

15 Stadius ML, Maynard C, Fritz JK, et al. Coronary anatomy and left ventricular function in the first 12 hours of acute myocardial infarction: The Western Washington Randomized Intracoronary Streptokinase Trial. Circulation 1985;72:292-301.

16 Habib GB, Heibig J, Forman SA, et al. Influence of coronary collateral vessels on myocardial infarct size in humans. Circulation 1991;83:739-46.

17 AIMS Trial Study Group. Effect of intravenous APSAC on mortality after acute myocardial infarction: preliminary report of a placebo-controlled clinical trial. Lancet 1988;i:545-9.

18 LATE Study Group. Late assessment of Thrombolytic Efficacy (LATE) study with alteplase 6-24 hours after onset of acute myocardial infarction. Lancet 1993;342:

19 EMERAS (Estudio Multicéntrico Estreptoquinasa Repúblicas de América del Sur) Collaborative Group Republicas de America del Sur) Collaborative Group. Randomised trial of late thrombolysis in patients with
suspected acute myocardial infarction. Lancet 1993;342: suspected

20 Simoons ML, Vos J, Tijssen JGP, et al. Long-term benefit of early thrombolytic therapy in patients with acute myocardial infarction: 5 year follow-up of a trial conducted by the Interuniversity Cardiology Institute of the Netherlands. F Am Coll Cardiol 1989;14:1609-15. 